\title{
Chymase Participates in Chronic Dermatitis by Inducing Eosinophil Infiltration
}

\author{
Yoshiaki Tomimori, Tsuyoshi Muto, Harukazu Fukami, Kayo Saito, Chika Horikawa, \\ Nobuo Tsuruoka, Masayuki Saito, Namino Sugiura, Kyoko Yamashiro, \\ Motoo Sumida, Saki Kakutani, and Yoshiaki Fukuda
}

Suntory Biomedical Research Limited, Wakayamadai, Shimamoto-cho, Mishima-gun, Osaka, Japan

SUMMARY: An epicutaneous application of 2,4-dinitrofluorobenzene (DNFB) to a mouse ear caused a transient skin swelling, and the repetition of the challenge enlarged the contact dermatitis. The repeated challenge with DNFB also induced eosinophil infiltration on the application site. Administration of a chymase inhibitor significantly inhibited the ear swelling as well as eosinophil accumulation. An intradermal injection of human chymase to the mouse ear also elicited transient skin swelling and eosinophil infiltration, both of which were augmented in proportion to the number of injections. Human serum albumin and heat-inactivated chymase failed to induce such skin reactions, suggesting the participation of proteolytic activity of the enzyme. In addition, chymase stimulated eosinophil migration in vitro in a concentration-dependent manner. Taken together, these observations suggest that mast cell chymase may contribute to development of the DNFB-induced dermatitis, probably by promoting eosinophil infiltration. It is therefore possible that chymase plays a role in pathogenesis of chronic dermatitis such as atopic dermatitis. (Lab Invest 2002, 82:789-794).

A topic dermatitis (AD) is a chronic eczematous skin disorder characterized by dry and itchy skin. The patients with $A D$ often have a family history of other allergic diseases including asthma and hay fever. Although $A D$ is known to be a manifestation of immediate hypersensitivity mediated by IgE, delayed-type hypersensitivity is also involved in the skin reaction of the patients (Tanaka et al, 1994; Varela et al, 1999). Interestingly, in mice, repeated application of contact sensitizing agents, such as 2,4-dinitrofluorobenzene (DNFB) and trinitrochlorobenzene, develops an immediate-type reaction, in contrast to a single application that causes a typical delayed-type reaction (Kitagaki et al, 1995, 1997). Repeated elicitation with such agents not only increases the serum level of $\lg \mathrm{E}$ but also induces Th2-type cytokine expression (Nagai et al, 1997b). In addition, mast cell accumulation occurs in the dermis because of the repeated challenge (Kitagaki et al, 1995), as is often observed in $A D$ patients. Therefore, this animal model is thought to be valuable for studying human $A D$.

Chymase is a chymotrypsin-like serine protease and is primarily stored in secretory granules of mast cells (Schwartz and Austen, 1980). Chymase cleaves a variety of physiological substances, including metalloproteases (Fang et al, 1997), procollagen (Kofford et al, 1997), precursor of interleukin $1 \beta$ (IL-1 $\beta$ ) (Mizutani et al, 1991b), and membrane-associated stem cell

DOI: 10.1097/01.LAB.0000018827.78602.F4

Received March 18, 2002.

Address reprint requests to: Dr. Yoshiaki Fukuda, Suntory Biomedical Research Limited, 1-1-1 Wakayamadai, Shimamoto-cho, Mishima-gun, Osaka 618-8503, Japan. E-mail: Yoshiaki_Fukuda@suntory.co.jp factor (Longley et al, 1997), while its precise role is not clear. Human mast cells are classified into two types, $\mathrm{MC}_{\mathrm{TC}}$ and $\mathrm{MC}_{\mathrm{T}}$, based on their composition of serine protease (Irani et al, 1986). $\mathrm{MC}_{\mathrm{TC}}$ contains both chymase and tryptase, while $\mathrm{MC}_{\mathrm{T}}$ expresses tryptase but not chymase. Because $\mathrm{MC}_{\mathrm{TC}}$ predominates in the skin (Irani et al, 1989), chymase has been implicated in the pathogenesis of skin disorders complicated by mast cell accumulation, eg, AD (DeMora et al, 1996; Tanaka et al, 1999) and scleroderma (Irani et al, 1992; Kakizoe et al, 2001).

Here, we report that the inhibitor for chymase inhibits the dermatitis induced by repeated challenge with DNFB, judging by the skin thickness and eosinophil infiltration, and that purified chymase elicits skin response similar to that induced by the DNFB painting. These findings suggest that chymase may participate in the pathogenesis of $A D$ by promoting eosinophil infiltration at the inflammation sites.

\section{Results}

\section{Effect of Chymase Inhibitor on Ear Swelling Induced by Repeated Challenge with DNFB}

As shown in Figure 1, an epicutaneous application of DNFB to the ears of $\mathrm{C} 3 \mathrm{H} / \mathrm{HeN}$ mice elicited a transient skin reaction, while painting with solvent for DNFB caused little effect on the ear thickness. Repeating the challenge with DNFB weekly for 6 weeks not only enhanced the transient response to DNFB, but also increased the baseline of ear thickness. Intraperitoneal administration of prednisolone (10 or $30 \mathrm{mg} / \mathrm{kg}$ ) 5 times a week for 37 days (36 times in total) reduced the increase of the ear thickness in a dose-dependent 


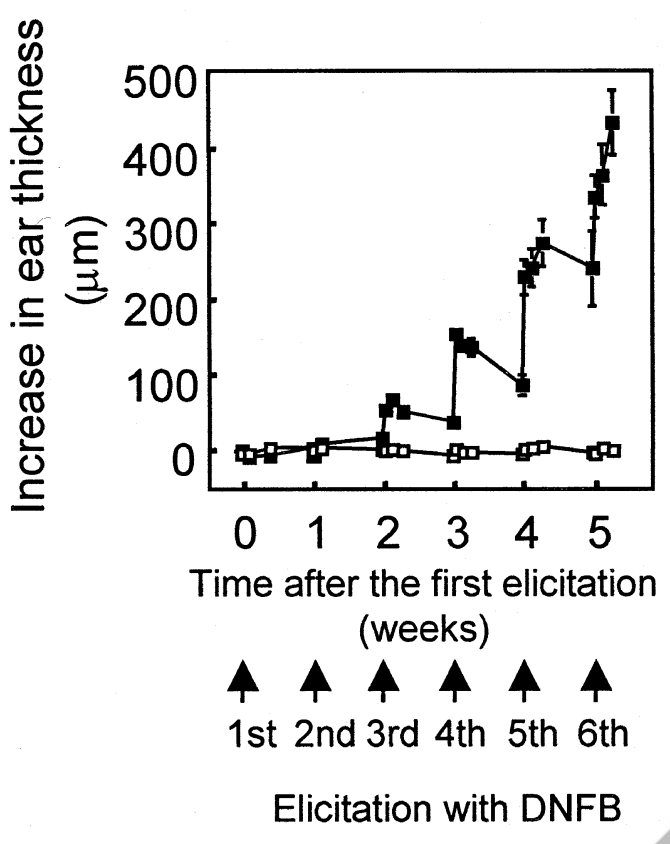

Figure 1.

Change in ear thickness by repeated challenge with 2,4-dinitrofluorobenzene (DNFB). Ear edema was induced by repeated painting with DNFB, and ear thickness was measured at $0,1,6,24$, and 48 hours after each painting using a thickness gauge. Increase in ear thickness was determined by subtracting the ear thickness before the first painting from that of each point after. The same volume of acetone/olive oil was painted on control mice. Closed square, painted with DNFB; Open square, painted with acetone/olive oil instead of DNFB. Data are mean \pm SEM. Arrows indicate the timing of the challenge with DNFB.
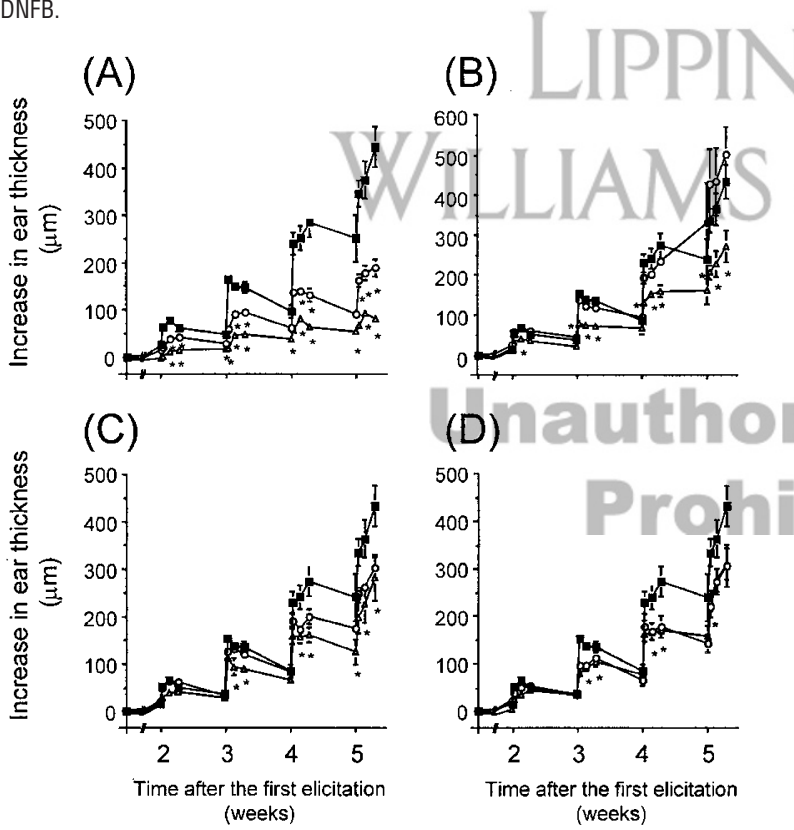

Figure 2.

Effect of chymase inhibitors on ear edema induced by repeated painting with DNFB. Ear edema was induced by repeated painting with DNFB, and ear thickness was measured at $0,1,6,24$, and 48 hours after each painting using a thickness gauge. Increase in ear thickness was determined by subtracting the ear thickness before the first painting from that of each point after. Chemicals were administered ip once a day, five times a week. Only the data after the third painting were shown. A, prednisolone; B, SUN-C7512; C, SUN-C8077; D, SUN-C8257. Closed square, vehicle; Open circle, $10 \mathrm{mg} / \mathrm{kg}$; Open triangle, 30 $\mathrm{mg} / \mathrm{kg}(\mathrm{A})$ or $50 \mathrm{mg} / \mathrm{kg}(\mathrm{B}-\mathrm{D})$. Data are mean \pm SEM *, $p<0.05$ as compared with the vehicle group (Dunnett's test, $n=6$ or 7 ). manner (Fig. 2A). That is, injection of prednisolone at $30 \mathrm{mg} / \mathrm{kg}$ significantly reduced the DNFB-induced ear swelling at $0,1,6,24$, and 48 hours after the third challenge with DNFB. The effect was milder at a dose of $10 \mathrm{mg} / \mathrm{kg}$, but statistical significance was detected at all the time points measured except at 48 hours after the third painting.

When chymase inhibitors were administered at 10 or $50 \mathrm{mg} / \mathrm{kg}$ with the same protocol as that of prednisolone, the DNFB-induced ear swelling was also reduced (Fig. 2, B to D). For example, SUN-C7512 at $50 \mathrm{mg} / \mathrm{kg}$ significantly suppressed the increase in ear thickness at 1, 6, 24, and 48 hours following the fourth challenge and thereafter, although SUN-C7512 at 10 $\mathrm{mg} / \mathrm{kg}$ showed little effect (Fig. 2B). A trend of decrease in the skin reaction was also observed when SUN-C7512 was given orally at $50 \mathrm{mg} / \mathrm{kg}$ (data not shown). Similar results were observed when other inhibitors, SUN-C8077 and SUN-C8257, were used; the effect of SUN-C8077 was dose-dependent, whereas the inhibition by SUN-C8257 seems saturated at $10 \mathrm{mg} / \mathrm{kg}$ (Fig. 2, C and D). These results suggest that mast cell chymase may be involved in the development of skin reaction induced by repeated painting with a contact sensitizing agent.

\section{Effect of Chymase Inhibitors on Eosinophil Accumulation in DNFB-Induced Dermatitis}

As shown in Figure 3, repeated challenge of DNFB weekly for 6 weeks increased the number of eosinophils in the skin lesion at 48 hours after the last challenge. Intraperitoneal administration of SUNC8257 (10 or $50 \mathrm{mg} / \mathrm{kg}$ ) 5 times a week for 6 weeks significantly suppressed the increase in the number of skin eosinophils (Fig. 3). There was also a tendency for SUN-C8077 to inhibit the eosinophil infiltration in a dose-dependent manner, though the inhibition was not statistically significant in this case. This finding

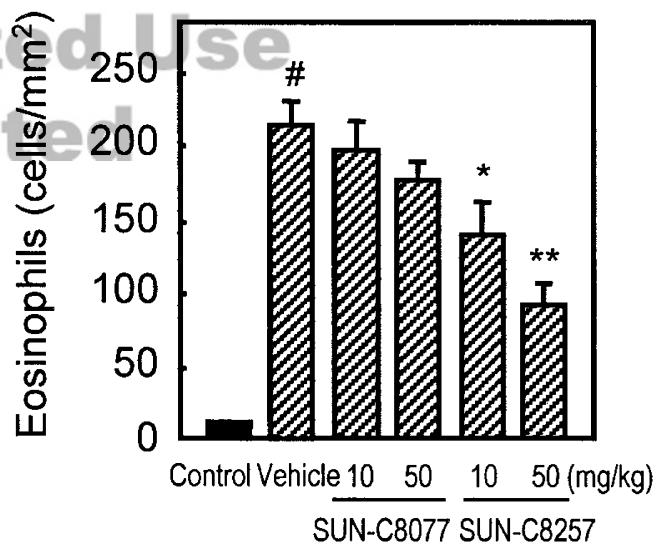

Figure 3.

Effect of chymase inhibitor on DNFB-induced eosinophil infiltration. Dermatitis was induced by repeated painting with DNFB, and the number of dermal eosinophils was determined 48 hours after the last painting as described in "Materials and Methods." Hatched bar, painted with DNFB; Closed bar, painted with acetone/olive oil. Data are mean \pm SEM \#, $p<0.01$ as compared with the control (acetone/olive oil) group; ${ }^{* *}, p<0.01$ as compared with vehicle group (Dunnett's test, $n=6$ or 7 ). 
suggests that chymase may be related to the eosinophil infiltration in the DNFB-induced dermatitis, and that the remission of ear swelling by chymase inhibitor may be associated with decrease of the eosinophil number.

\section{Skin Reaction Induced by Intradermal Injection with Human Chymase}

To further elucidate the role of chymase in dermatitis, recombinant human chymase was injected intradermally into the mouse ear 5 times on a weekly basis. As shown in Figure 4A, an injection of human chymase caused a transient ear swelling. The chymase-induced cutaneous reaction resembled the reaction induced by DNFB in that the transient edematous response was augmented in proportion to the number of the challenges. Peak increase of ear thickness after the fifth injection of chymase was approximately $70 \mu \mathrm{m}$, whereas after the first injection it was $35 \mu \mathrm{m}$ at most. Neither heat-inactivated chymase (Fig. 4A) nor human serum albumin (Fig. 4B) induced ear swelling, suggesting that chymase-induced skin reaction is dependent on its proteolytic activity but not its antigenicity.

\section{Effect of Chymase Injection on Dermal Eosinophil Number}

Next, recombinant human chymase was injected intradermally into the mouse ear weekly, and change of eosinophil number at the injection site was examined. As shown in Figure 5, dermal eosinophil number of chymase-injected mice was approximately 7.6-fold and 21-fold at 7 days after the first and fourth injection of chymase, respectively, as compared with that of the corresponding control. The result is consistent with the data of $\mathrm{He}$ and Walls (1998) who have shown that human chymase induces the accumulation of inflam-

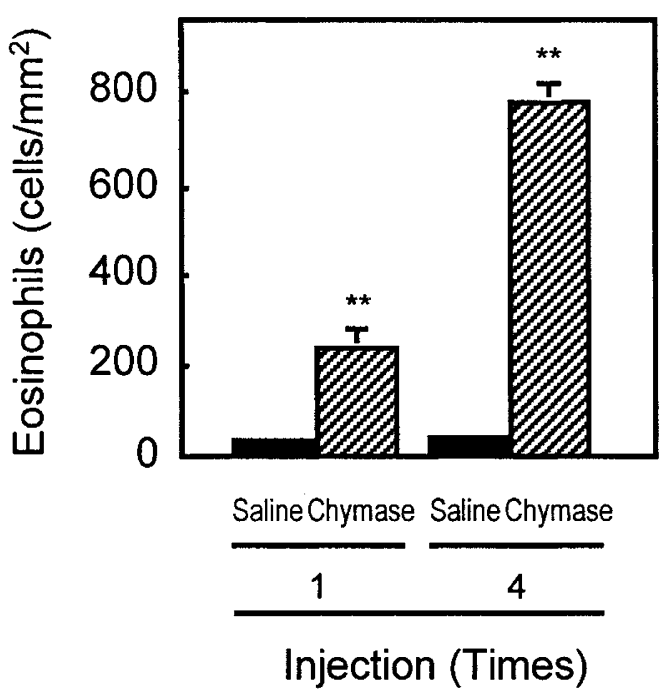

Figure 5.

Induction of eosinophil accumulation induced by chymase injection. Human chymase $(2.0 \mu \mathrm{g})$ (hatched bar) or the same volume of saline (closed bar) was injected intradermally to the mouse ear 4 times at 7-day intervals, and dermal eosinophil number was determined 7 days after the injection as described in "Materials and Methods." Data are mean \pm SEM **, $p<0.01$ as compared with the corresponding control (Student's $t$ test, $n=5$ ).

matory cells including eosinophils in the peritoneal cavity of mice and the skin of guinea pigs.

\section{Chemotactic Activity of Human Chymase for Eosinophils}

To clarify the mechanism by which chymase induces eosinophil accumulation, the effect of human chymase on migration of human peripheral eosinophils was examined in vitro. As shown in Figure 6, platelet activating factor (PAF) $(0.01-0.1 \mu \mathrm{M})$ stimulated eosinophil migration in a concentrated manner. Similarly, human chymase $(0.5-1.0 \mu \mathrm{M})$ enhanced the migration
(A)

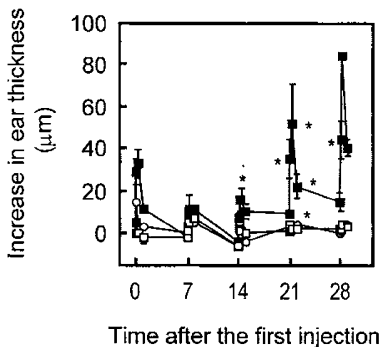
(Days)
(B)

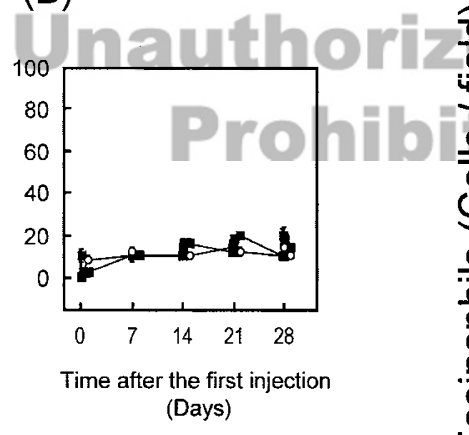

Figure 4.

Change in ear thickness induced by injection with human chymase; $2.0 \mu \mathrm{g}$ of human chymase $(A)$ or human serum albumin $(B)$ was injected intradermally to mouse ear at 7-day intervals and ear thickness was measured at 0,1, 6, and 24 hours after each injection using a thickness gauge. Abilities of heatinactivated chymase and saline to induce skin reaction were also examined. Increase in ear thickness was determined by subtracting the ear thickness before the first injection with human chymase from that of each point after. Closed square, human chymase (A) or human serum albumin (B); open square, heat-inactivated human chymase; open circle, saline. Data are mean \pm SEM ${ }^{*}, p<0.05 ;{ }^{* *}, p<0.01$ as compared with the saline group (Student's $t$ test, $n=5)$.

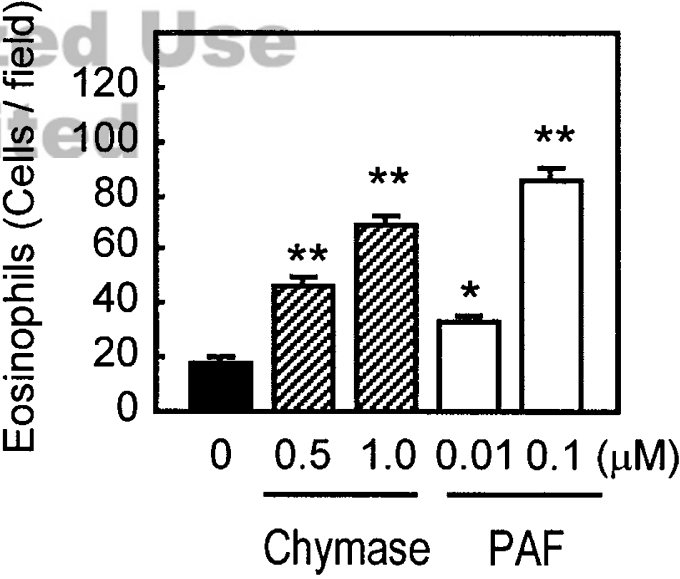

Figure 6.

Effect of human chymase on migration of human eosinophils in vitro. Human eosinophils were isolated and chemotactic assay was performed as described in "Materials and Methods." Data are expressed as migrated cells per high power field (mean $\pm \mathrm{SE})(n=3)$. Hatched bar, human chymase; Closed bar, no stimulant; Open bar, platelet activating factor (PAF). ${ }^{*}, p<0.05 ;{ }^{* \star}, p<$ 0.01 as compared with the control (Dunnett's test). 
of eosinophils, although the minimum effective concentration of human chymase appeared to be higher than that of PAF. This finding is consistent with that of Tani et al (2000) and suggests that chymase-induced eosinophil infiltration in mice may be mediated by the chemotactic activity of chymase.

\section{Discussion}

Topical application with DNFB elicited a transient skin swelling, and repeating the application enlarged the reaction (Fig. 1). Administration of chymase inhibitor significantly prevented development of ear swelling induced by the DNFB challenge (Fig. 2). Repeated injection of chymase caused a cutaneous reaction similar to the DNFB-induced dermatitis (Fig. 4). These results suggest the involvement of mast cell chymase in the development of dermatitis induced by repeated challenges with a contact-sensitizing agent. This idea is supported by the result of the study using mast-celldeficient mice, ie, the magnitude of the skin reaction induced by repeated painting with trinitrochlorobenzene is much less in mast cell-deficient mice WBB6F1-W/W than in their litter mates WBB6F1-+/+ (Kitagaki et al, 1997).

The mechanism by which the DNFB-induced skin response increases in proportion to the number of the challenge is unclear at present. The effect of chymase inhibitor on contact dermatitis induced by a single application of DNFB was little, if any (data not shown). Thus, the mechanisms that mediate the skin reaction induced by single and repeated challenge with a contact sensitizing agent appear to be different from each other. Both DNFB painting and chymase injection caused eosinophil accumulation in mice (Figs. 3 and 5), and the chymase inhibitor reduced the DNFBinduced eosinophil accumulation (Fig. 3). These findings suggest a hypothesis that eosinophils may be crucial for development of the dermatitis induced by repeated painting with DNFB and that the effect of the chymase inhibitor on ear edema in the model may be the result of the inhibition of eosinophil infiltration.

Human chymase stimulated migration of human eosinophils in vitro (Fig. 6). This finding naturally indicates that the DNFB- and chymase-induced eosinophil accumulation in mice is, at least in part, due to the chemotactic activity of chymase. The direct action of chymase in stimulating eosinophil migration might be mediated via putative receptor(s), such as protease-activated receptor(s) (PAR) (Cocks and Moffatt, 2000) like cathepsin G, an enzyme closely related to chymase, which acts on the platelet by interacting with PAR-4 (Sambrano et al, 2000). An alternative explanation for chymase-induced eosinophil migration is that chymase promotes production of chemokines such as eotaxin. Our preliminary experiment shows that eotaxin concentration is undetectable in the chemotaxis chamber even after the treatment with chymase for 1 hour, indicating that eotaxin is not involved in the chemotactic activity of chymase. However, the possibility that chymase-induced eosinophil migration is mediated by other chemokines is not completely denied.

The eosinophil infiltration induced by chymase injection in mice could also be explained by the ability of chymase to produce IL-1 $\beta$ that is a potent inducer of eosinophil accumulation (Sanz et al, 1995) because chymase can cleave IL-1 $\beta$ precursor to produce an active IL-1 $\beta$ (Mizutani et al, 1991b). Epidermal keratinocytes produces an IL-1 $\beta$ precursor but lacks an activity of interleukin 1 converting enzyme (Mizutani et al, 1991a), and mast cell chymase could, therefore, process the IL- $1 \beta$ precursor released by keratinocytes in epidermis at inflammatory sites. In fact, IL- $1 \beta$ species corresponding to that processed by chymase was detected in psoriatic scales (Lundqvist and Egelrud, 1997) and human stratum corneum (Brattsand and Egelrud, 1998).

One of the most interesting features of the dermatitis induced by repeated painting of contact sensitizing agents is a shift of Th1-type to Th2-type reaction (Kitagaki et al, 1995). Nagai et al (1997a) have shown that FK-506 and cyclosporin A, which suppressed ear edema induced by repeated challenge with DNFB, inhibited synthesis of interferon $\gamma$ but not interleukin 4 in this model. They have concluded that these immunosuppressants inhibit DNFB-induced contact dermatitis, probably by a selective inhibitory action upon Th1 cells. In contrast, chymase inhibitor SUN-C8077 affected neither interferon $\gamma$ nor interleukin 4 levels in the serum in the DNFB-induced dermatitis, although SUN-C8257 slightly decreased interleukin 4 levels (data not shown). Thus, unlike the immunosuppressants, inhibition of the skin reaction by chymase inhibitor is presumably independent on Th1/Th2 balance.

In conclusion, the data in this study suggest that mast cell chymase participates in development of skin reactions induced by repeated application with contact sensitizing agents, probably by affecting eosinophil infiltration. Because the DNFB-induced dermatitis employed in this study is thought to be an animal model for chronic dermatitis including human $A D$, our data also show that chymase may play an important role in pathogenesis of $A D$, and chymase inhibitor may be beneficial for treatment of AD.

\section{Materials and Methods}

\section{Mice}

$\mathrm{C} 3 \mathrm{H} / \mathrm{HeN}$ mice were purchased from CLEA Japan, Inc. (Tokyo, Japan). All animal experiments were performed according to the Guideline for Animal Experimentation (Japanese Association for Laboratory Animal Science, 1987).

\section{DNFB-Induced Dermatitis}

Allergic dermatitis was induced by repeated topical application with DNFB as described previously (Nagai et al, 1997b). Briefly, $25 \mu \mathrm{l}$ of $0.15 \%$ DNFB in acetone/ olive oil (3:1) was applied to each side of right ears of $\mathrm{C} 3 \mathrm{H} / \mathrm{HeN}$ mice 6 times at 7-day intervals. Ear thickness was measured $0,1,6,24$, and 48 hours after 
each painting using a thickness gauge (Digimatic Indicator, Mitsutoyo, Tokyo, Japan), and increase in ear thickness was determined by subtracting ear thickness before the first painting from that of each point after. The same volume of acetone/olive oil was painted on control mice.

\section{Chymase Inhibitors}

Inhibitors for chymase have been synthesized as described previously (Fukami et al, 2000). The inhibitors employed in this study are 3-[ 4-(pyrazol-3yl)phenylsulfonyl]-7-chloroquinazorine 2, $4(1 \mathrm{H}, 3 \mathrm{H})$ dione (SUN-C7512), 3-(3-aminophenylsulfonyl)-7chloroquinazorine 2, 4(1H, 3H)-dione (SUN-C8077), 3-[(3-amino-4-carboxy) phenylsulfonyl]-7-chloroquinazorine 2, and 4(1H, 3H)-dione (SUN-C8257). IC50 values of SUN-C7512, SUN-C8077, and SUN-C8257 for human chymase are $0.070 \mu \mathrm{M}, 0.36 \mu \mathrm{M}$, and $0.13 \mu \mathrm{M}$, respectively. None of them shows an inhibitory effect on bovine trypsin even at $10 \mu \mathrm{M}$. The inhibitors were suspended in $0.5 \%$ hydroxy propyl cellulose (Nippon Soda Company, Ltd., Tokyo, Japan) and administered ip once a day, five times a week (from Monday to Friday). As a control, prednisolone (Nacalai Tesque, Inc., Kyoto, Japan) was similarly suspended in $0.5 \%$ hydroxy propyl cellulose and administered.

\section{Histological Analysis}

Ear samples were fixed in 10\% (vol/vol) buffered formalin, embedded in paraffin, sectioned at $5 \mu \mathrm{m}$, and then stained with Fast Green FCF (Fluka, SigmaAldrich, Tokyo, Japan) for staining of eosinophils. The number of eosinophils was determined by counting the stained cells in 10 high-power fields for each section using an ocular grid. $1 \mathrm{~L}$ I

\section{Recombinant Human Chymase}

Human chymase was expressed in $\mathrm{CHO}$ cells using the secretion and activation pathway of trypsin II (Yamashiro et al, 1997). Briefly, cDNA for mature human chymase (79-756) (Urata et al, 1991) was amplified by PCR, and the product was cloned into pDE in conjunction with 23 amino acid residues of human trypsin II precursor that includes signal sequence and cleavage site for enterokinase. The resultant plasmid was transfected to $\mathrm{CHOdhfr}$-, and the transfectant was selected as described (Tsuruoka et al, 1993). The fusion protein in culture supernatant of the transfectant was concentrated with HiTrap Heparin column (Amersham Pharmacia Biotech, Tokyo, Japan) and cleaved with recombinant enterokinase (Invitrogen, Carlsbad, California). The mature form of human chymase was then purified with Heparin 5PW column (Tosoh Corporation, Tokyo, Japan), and the purity was assessed by SDS polyacrylamide gel electrophoresis with 10 to $20 \%$ gradient gel (10/20 Multi gel, Daiich Pure Chemicals, Tokyo, Japan). Activity of recombinant human chymase was measured using 1 mm Suc-Ala-Ala-Pro-Phe-MCA (Peptide Institute, Osaka, Japan) in $0.1 \mathrm{M} \mathrm{Tris} / \mathrm{HCl}, \mathrm{pH}$ 8.0. For heat inactivation of human chymase, $0.1 \mathrm{mg} / \mathrm{ml}$ of the chymase solution was incubated for 2 hours at $50^{\circ} \mathrm{C}$ followed by boiling for 5 minutes.

\section{Chymase Injection}

Human recombinant chymase was dissolved in saline and $20 \mu \mathrm{l}$ of the chymase solution was injected intradermally $(2.0 \mu \mathrm{g} / \mathrm{site})$ to right ear of mice 5 times at 7-day intervals. Ear thickness was measured 0, 1, 6, and 24 hours after each injection using a thickness gauge, and increase in ear thickness was determined as described above. The same volume of saline, heat-inactivated human chymase or human serum albumin (Sigma-Aldrich) $(2.0 \mu \mathrm{g} / \mathrm{site})$ was injected in control mice.

\section{Isolation of Eosinophils}

Human eosinophils were isolated from heparinized whole blood of healthy volunteers. Briefly, whole blood was mixed with $6 \%$ dextran $(1: 5$, vol/vol), and erythrocytes were sedimented by settling for 1 hour at $37^{\circ} \mathrm{C}$. The clear top fraction containing granulocytes was layered on Ficoll-Paque (Pharmacia Biotech, Uppsala, Sweden), and centrifuged at $500 \times g$ for 30 minutes to collect granulocytes. Eosinophils were isolated from the granulocyte fraction by negative immunomagnetic selection using anti-CD16 MACS-particles (Miltenyi Biotec, Auburn, California) according to the manufacturer's instruction. Purity of eosinophils was determined by Fast Green staining and was usually $>98 \%$.

\section{Chemotaxis Assay}

Chemotaxis assay was performed using a 48-well microchemotaxis chamber in which a polycarbonate filter with a pore diameter of $5 \mu \mathrm{m}$ (Neuroprobe, Cabin John, Maryland) separates the upper and the lower compartments. $50 \mu \mathrm{l}$ of cell suspension $\left(4 \times 10^{6}\right.$ cells per $\left.\mathrm{ml}\right)$ was placed in the upper chamber and aliquots of either human chymase or PAF (Sigma-Aldrich) was added in the lower chamber. The chamber was incubated for 1 hour at $37^{\circ} \mathrm{C}$ in an atmosphere of $5 \% \mathrm{CO}_{2}$. Then, the filter was removed, and cells on the filter were fixed and stained with Hemacolor (Merck Diagnostics, Darmstadt, Germany). The migrated cells adhered to the distal part of the filter were counted in three high-power fields for each well.

\section{Statistical Analysis}

The statistical analysis was performed with Dunnett's multiple comparison test or Student's $t$ test using SuperANOVA (Abacus Concepts, Berkeley, California) or Statview (SAS Institute Inc., Cary, North Carolina), respectively. A $p$ value less than 0.05 was considered significant.

\section{Acknowledgments}

We are grateful to Drs. Tatsuro Nishihara and Toshihiro Nakanishi for their helpful advice and valuable discussion during this study. 


\section{References}

Brattsand $M$ and Egelrud T (1998). Purification and characterization of interleukin $1 \beta$ from human plantar stratum corneum. Evidence of interleukin $1 \beta$ processing in vivo not involving interleukin $1 \beta$ convertase. Cytokine 10:506-513.

Cocks TM and Moffatt JD (2000). Protease-activated receptors: sentries for inflammation? Trends Pharmacol Sci 21:103-108.

DeMora F, Garcia G, Puigdemont A, Arboix M, and Ferrer L (1996). Skin mast cell releasability in dogs with atopic dermatitis. Inflamm Res 45:424-427.

Fang KC, Raymond WW, Blount JL, and Caughey GH (1997). Dog mast cell $\alpha$-chymase activates progelatinase $\mathrm{B}$ by cleaving the Phe88-Gln89 and Phe91-Glu92 bonds of the catalytic domain. J Biol Chem 272:25628-25635.

Fukami H, Imajo S, Ito A, Kakutani S, Shibata H, Sumida M, Tanaka T, Niwata S, Saitoh M, Kiso Y, Miyazaki M, Okunishi $\mathrm{H}$, Urata $\mathrm{H}$, and Arakawa K (2000). Substituted 3-phenylsulfonylquinazoline-2,4-dione derivatives as novel nonpeptide inhibitors of human heart chymase. Drug Des Discov 17:69-84.

He S and Walls AF (1998). Human mast cell chymase induces the accumulation of neutrophils, eosinophils and other inflammatory cells in vivo. Br J Pharmacol 125:1491-1500.

Irani AA, Schechter NM, Craig SS, DeBlois G, and Schwartz LB (1986). Two types of human mast cells that have distinct neutral protease compositions. Proc Natl Acad Sci USA 83:4464-4468.

Irani AM, Bradford TR, Kepley CL, Schechter NM, and Schwartz LB (1989). Detection of MCT and MCTC types of human mast cells by immunohistochemistry using new monoclonal anti-tryptase and anti-chymase antibodies. $\mathrm{J}$ Histochem Cytochem 37:1509-1515.

Irani AM, Gruber BL, Kaufman LD, Kahaleh MB, and Schwartz LB (1992). Mast cell changes in scleroderma. Presence of MCT cells in the skin and evidence of mast cell activation. Arthritis Rheum 35:933-939.

Kakizoe E, Shiota N, Tanabe Y, Shimoura K, Kobayashi Y, and Okunishi H (2001). Isoform-selective upregulation of mast cell chymase in the development of skin fibrosis in scleroderma model mice. J Invest Dermatol 116:118-123.

Kitagaki H, Fujisawa S, Watanabe K, Hayakawa K, and Shiohara T (1995). Immediate-type hypersensitivity response followed by a late reaction is induced by repeated epicutaneous application of contact sensitizing agents in mice. J Invest Dermatol 105:749-755.

Kitagaki H, Ono N, Hayakawa K, Kitazawa T, Watanabe K, and Shiohara T (1997). Repeated elicitation of contact hypersensitivity induces a shift in cutaneous cytokine milieu from a Thelper cell type 1 to a T helper cell type 2 profile. $\mathrm{J}$ Immunol 159:2484-2491.

Kofford MW, Schwartz LB, Schechter NM, Yager DR, Diegelmann RF, and Graham MF (1997). Cleavage of type I procollagen by human mast cell chymase initiates collagen fibril formation and generates a unique carboxyl-terminal propeptide. J Biol Chem 272:7127-7131.

Longley BJ, Tyrrell L, Ma Y, Williams DA, Halaban R, Langley K, Lu HS, and Schechter NM (1997). Chymase cleavage of stem cell factor yields a bioactive, soluble product. Proc Natl Acad Sci USA 94:9017-9021.
Lundqvist EN and Egelrud T (1997). Biologically active, alternatively processed interleukin- $1 \beta$ in psoriatic scales. Eur J Immunol 27:2165-2171.

Mizutani H, Black R, and Kupper TS (1991a). Human keratinocytes produce but do not process pro-interleukin-1 (IL-1) $\beta$. Different strategies of IL-1 production and processing in monocytes and keratinocytes. J Clin Invest 87:1066-1071.

Mizutani H, Schechter N, Lazarus G, Black RA, and Kupper TS (1991b). Rapid and specific conversion of precursor interleukin $1 \beta$ (IL-1 $\beta$ ) to an active IL-1 species by human mast cell chymase. J Exp Med 174:821-825.

Nagai $H$, Hiyama $H$, Matsuo $A$, Ueda $Y$, Inagaki $N$, and Kawada K (1997a). FK-506 and cyclosporin A potentiate the IgE antibody production by contact sensitization with hapten in mice. J Pharmacol Exp Ther 283:321-327.

Nagai $\mathrm{H}$, Matsuo A, Hiyama $\mathrm{H}$, Inagaki $\mathrm{N}$, and Kawada $\mathrm{K}$ (1997b). Immunoglobulin E production in mice by means of contact sensitization with a simple chemical, hapten. J Allergy Clin Immunol 100(Suppl):39-44.

Sambrano GR, Huang W, Faruqi T, Mahrus S, Craik C, and Coughlin SR (2000). Cathepsin G activates proteaseactivated receptor-4 in human platelets. J Biol Chem 275: 6819-6823.

Sanz MJ, Weg VB, Bolanowski MA, and Nourshargh S (1995). IL-1 is a potent inducer of eosinophil accumulation in rat skin. Inhibition of response by a platelet-activating factor antagonist and an anti-human IL-8 antibody. J Immunol 154:1364-1373.

Schwartz LB and Austen KF (1980). Enzymes of the mast cell granule. J Invest Dermatol 74:349-353.

Tanaka M, Aiba S, Matsumura N, Aoyama H, Tabata N, Sekita $Y$, and Tagami H (1994). IgE-mediated hypersensitivity and contact sensitivity to multiple environmental allergens in atopic dermatitis. Arch Dermatol 130:1393-1401.

Tanaka K, Sugiura H, Uehara M, Sato H, Hashimoto-Tamaoki $\mathrm{T}$, and Furuyama (1999). Association between mast cell chymase genotype and atopic eczema: Comparison between patients with atopic eczema alone and those with atopic eczema and atopic respiratory disease. J Clin Exp Allergy 29:800-803.

Tani K, Ogushi F, Kido H, Kawano T, Kunori Y, Kamimura T, Cui $P$, and Sone $S$ (2000). Chymase is a potent chemoattractant for human monocytes and neutrophils. J Leukoc Biol 67:585-589.

Tsuruoka N, Yamashiro K, and Tsujimoto M (1993). Purification of soluble murine interleukin 5 (IL-5) receptor $\alpha$ expressed in Chinese hamster ovary cells and its action as an IL-5 antagonist. Arch Biochem Biophys 307:133-137.

Urata H, Kinoshita A, Perez DM, Misono KS, Bumpus FM, Graham RM, and Husain A (1991). Cloning of the gene and CDNA for human heart chymase. J Biol Chem 266:17173-17179.

Varela P, Selores M, Gomes E, Silva E, Matos E, dos Santos L, Amado J, and Massa A (1999). Immediate and delayed hypersensitivity to mite antigens in atopic dermatitis. Pediatr Dermatol 16:1-5.

Yamashiro K, Tsuruoka N, Kodama S, Tsujimoto M, Yamamura $\mathrm{Y}$, Tanaka $\mathrm{T}$, Nakazato $\mathrm{H}$, and Yamaguchi $\mathrm{N}$ (1997). Molecular cloning of a novel trypsin-like serine protease (neurosin) preferentially expressed in brain. Biochim Biophys Acta 1350:11-14. 